\title{
EDUCAÇÃO E DESENVOLVIMENTO SUSTENTÁVEL NA AgENDA 21 BRASILEIRA*
}

\author{
Cristina Teixeira ${ }^{* *}$
}

\section{RESUMO}

O presente artigo faz uma análise crítica das diretrizes relativas à educação na Agenda 21 brasileira, apresentada como um instrumento de planejamento para o desenvolvimento sustentável que compatibiliza conservação ambiental, justiça social e crescimento econômico. Na Agenda 21 brasileira, a educação deve promover a inclusão social e contribuir para a inserção do Brasil na economia globalizada, inserção esta definida como condição para o desenvolvimento sustentável. Observa-se que, em última instância, as propostas para a educação na Agenda 21 brasileira são funcionais à inserção do país ao mesmo modelo socioeconômico no qual está a raiz da insustentabilidade.

Palavras-chave: Educação e desenvolvimento sustentável. Agenda 21 brasileira.

\section{INTRODUÇÃO}

As conclusões da Conferência das Nações Unidas sobre o Meio Ambiente e Desenvolvimento (Cnumad), realizada em 1992, na cidade do Rio de Janeiro, foram apresentadas na Agenda 21 global, documento definido como um programa de ação para o desenvolvimento sustentável que compatibiliza a conservação ambiental, a justiça social e a eficiência econômica. Este documento define desenvolvimento sustentável como aquele que deve atender às necessidades do presente, sem comprometer o atendimento das necessidades das gerações futuras. Para a promoção do desenvolvimento sustentável, o mesmo documento atribui à educação,

\footnotetext{
* Artigo recebido em 22/02/2008 e aprovado em 6/06/2008.

** Doutora em Meio Ambiente e Desenvolvimento. Professora do Programa de Pós-Graduação em Educação da UFPR.
} 
ao lado de outras instituições sociais, a responsabilidade de contribuir para a promoção da sustentabilidade social, uma das dimensões do desenvolvimento sustentável. Ao lado da sustentabilidade social estão as sustentabilidades ecológica, ambiental, política, econômica, demográfica, cultural, constitucional e espacial.

A Agenda 21 global foi considerada um documento consensual, no qual a noção de desenvolvimento sustentável adotada pretendia superar as divergências do debate em torno da relação entre crescimento econômico e conservação dos recursos naturais. Participaram desse debate governos de Estado e a sociedade civil, envolvendo organizações não-governamentais, intelectuais, cientistas, religiosos e instituições econômicas, dentre elas, o Fundo Monetário Internacional (FMI), o Acordo Geral de Tarifas e Comércio (Gatt) e o Banco Mundial. Todos se dispuseram a discutir o desenvolvimento econômico e social a partir da perspectiva da sustentabilidade global (LEIS, 1996).

Como determina a Agenda 21 global, os países signatários deste documento, dentre eles o Brasil, devem incorporar os princípios nela contidos em suas políticas públicas. Em 1997, o governo brasileiro, através do Ministério do Meio Ambiente, dos Recursos Hídricos e da Amazônia Legal (MMA), designa uma Comissão de Políticas de Desenvolvimento Sustentável e da Agenda 21 Nacional (CPDS), para elaborar e implementar a Agenda 21 brasileira. Para isto, seminários e oficinas foram organizados com representantes de diferentes regiões do país, de diversos setores do Estado e da sociedade civil. Deste processo resultou a Agenda 21 brasileira - Bases para discussão. Publicada em 2000, tornou-se referência para a elaboração da Agenda 21 brasileira. Sua implantação iniciou-se em 2003, apesar de a publicação ocorrer somente em 2004.

A Agenda 21 brasileira foi elevada a condição de Programa do Plano Plurianual do Governo (PPA 2004/2007) e, em decorrência, oficialmente incorporada à política de desenvolvimento do país. Atualmente, é considerada pelo MMA "um dos grandes instrumentos de formação de políticas públicas no Brasil" (MMA, 2005a). Além disso, o MMA instituiu o Programa Agenda 21 que previu a implantação da Agenda 21 brasileira, a implantação das Agendas 21 locais e a formação continuada em Agenda 21 (MMA, 2005a, 2005b).

Se a Agenda 21 brasileira tornou-se um documento importante na formação de políticas públicas, o que está nela contido sobre a educação 
para o desenvolvimento sustentável deve ser considerado. Isto deve ser realizado, antes de tudo, entendendo o desenvolvimento sustentável que define a finalidade da educação.

Embora a proposição de desenvolvimento sustentável legitimada pela Cnumad pretenda ser consensual, o contrário pode ser observado nos debates sobre as interpretações, os limites e a viabilidade desta proposição. Dentre as diferentes considerações sobre os problemas do desenvolvimento sustentável estão aquelas que identificam a sua funcionalidade à lógica da produção capitalista, não sendo capaz, portanto, de enfrentar as causas estruturais da insustentabilidade ambiental e socioeconômica.

O presente artigo considera que essa funcionalidade pode ser observada na Agenda 21 brasileira, e a educação para o desenvolvimento sustentável, por ela proposta, estabelece suas diretrizes em função desse modelo de desenvolvimento. Neste caso, a educação deve contribuir para a inserção do país na globalização, meta a ser atingida para garantir a sustentabilidade social do desenvolvimento. Para isto, a educação estabelece como principal objetivo a formação para a inclusão social, no sentido da integração ao modelo de sociedade que mantém as causas estruturais da insustentabilidade socioeconômica e ambiental. Ou seja, considerando a globalização como "um conjunto de dispositivos político-econômicos para a organização da economia global, conduzido pela necessidade de manter o sistema capitalista mais do que qualquer outro conjunto de valores" (DALE, 2004, p. 436), a educação para o desenvolvimento sustentável - que pressupõe a inserção do país na globalização - identifica-se com a funcionalidade anteriormente citada.

\section{As CAUSAS DA INSUSTENTABILIDADE E OS LIMITES DO DESENVOLVIMENTO} SUSTENTÁVEL

Para refletir sobre a possibilidade de uma sociedade ecológica e socialmente sustentável é necessário identificar as causas da insustentabilidade que estão relacionadas à forma como a produção material se organiza política, social e culturalmente. Tal reflexão foi realizada por alguns autores que estabeleceram a relação entre crise ambiental, insustentabilidade e lógica da produção capitalista.

Em 1968, Habermas referia-se à crise ecológica como resultado do desenvolvimento do capitalismo avançado. O crescimento da população 
e da produção encontraria limites definidos pela capacidade biológica do ambiente. $\mathrm{O}$ processo de crescimento econômico inerente ao capitalismo não possuía condições de controle desse crescimento dentro do sistema que o gerou. Logo, para resolver a crise ambiental, seria necessário que o modelo de crescimento econômico vigente sofresse mudanças estruturais, nas quais haveria o planejamento da produção a partir de valores de uso, caracterizando o crescimento qualitativo. Esta solução só é possível se o sistema que orienta o desenvolvimento de suas forças produtivas a partir dos valores de troca violar sua própria lógica (HABERMAS, 1980, p. 59).

Ao se referir aos limites do desenvolvimento sustentável, Foladori (1999) considera que a crise ambiental é resultado do modo de produção capitalista, cuja lei determinante é a busca ilimitada de lucro. O desenvolvimento industrial, a tecnologia ou outros aspectos que possam aparecer como causadores da crise ambiental são determinados por relações sociais de produção. Logo, intenções de compatibilizar a sustentabilidade com as relações sociais de produção capitalistas estão fadadas ao fracasso, pois

las tendencias intrínsecas al incremento de la ganancia capitalista, implica comportamientos forzosos sobre el medio ambiente [...] No es una cuestión de voluntad, es una relación necesaria cuando existe competencia mercantil [...] las relaciones capitalistas no condicen con un desarrollo sustentable. (Foladori, 1999, p. 209-210)

Castells (2000) atribui ao modo de desenvolvimento industrial - e às suas conseqüências sociais - a responsabilidade pelos problemas ambientais. Para resolvê-los, é necessário uma transformação nos meios de produção e de consumo, na organização social e em nossas vidas pessoais. Para o mesmo autor, o ambientalismo indica a necessidade dessa transformação social ao propor a correção da relação entre o homem e seu ambiente natural. Para isto, é necessário transgredir "a lógica estrutural e institucional atualmente predominante" (CASTELLS, 2000, p. 143). Assim como os demais autores, é a natureza dos sistema que deve ser transformada.

Nos anos 70, o crescimento econômico foi redefinido a partir da necessidade de se considerar os limites do meio ambiente, particularmente os limites de exploração dos recursos naturais. As discussões, inicialmente polarizadas entre manutenção do modelo de crescimento econômico, 
responsável pelo desenvolvimento e pela conservação dos recursos naturais, sofreram mudanças. À medida que os problemas ambientais se revelavam cada vez mais complexos, os programas de desenvolvimento calcados no mesmo modelo de crescimento econômico se impunham, exigindo novos arranjos entre os dois pólos dessas discussões. Onde se observava incompatibilidade, surge a possibilidade da convivência entre crescimento e conservação, coroada pela noção de desenvolvimento sustentável lançada em 1987 no Relatório Brundtland.

O potencial transformador do ambientalismo, particularmente em suas origens, caracterizado pela identificação das causas da insustentabilidade na sociedade capitalista foi, gradativamente, diluído pela racionalidade econômica dominante (CASTELLS, 2000, p. 273). Isto pode ser observado através do desenvolvimento do Capitalismo verde, no qual "seriam preservados não apenas os recursos naturais, mas também e acima de tudo, infelizmente, as relações de produção existentes" (VARGAS, 1999, p. 230).

No mesmo sentido, Leff (2000, p. 291) afirma o seguinte:

Se nos anos setenta a crise ambiental levou a proclamar a necessidade de travar o crescimento, antes que se atingisse o colapso ecológico, nos anos noventa a dialética da questão ambiental produziu a sua negação: hoje o discurso neoliberal afirma o desaparecimento da contradição entre ambiente e crescimento [...] as milagrosas leis de mercado encarregam-se de ajustar os desequilíbrios ecológicos e as diferenças sociais gerando a eqüidade e sustentabilidade.

Antes mesmo da Rio 92, Lélé (1991) identificava que o ambientalismo e os desenvolvimentistas avessos à mudança da lógica do sistema produtivo, colocaram de lado suas diferenças e uniram-se em torno do modelo de desenvolvimento sustentável. Este foi considerado a saída para os problemas dos limites ambientais do crescimento econômico e, também, para os problemas sociais - pobreza e desigualdade social. Essa união foi regida pelo imperativo da possibilidade: a possibilidade de continuidade do sistema produtivo e das relações sociais que o sustentam, mantendo as causas estruturais da insustentabilidade. Isto pode ser observado no discurso do secretário de Políticas para o Desenvolvimento Sustentável do governo federal: "A Agenda 21 vem se constituindo [...] num processo social no qual os atores vão pactuando paulatinamente novos consensos e montando uma Agenda possível rumo ao futuro que 
se deseja sustentável" (MMA, 2007, grifos meu). Diante dos avanços das discussões sobre o desenvolvimento sustentável e dos obstáculos reais à sua implantação, este desenvolvimento deixa de ser meta e passa para a categoria - não objetiva - de desejo.

O desenvolvimento sustentável, como saída para a convivência entre o capitalismo e a conservação, torna-se funcional ao modelo de crescimento econômico responsável pela insustentabilidade ecológica e social. Ao adotá-lo, a Agenda 21 brasileira, como programa e instrumento de formação de políticas públicas, estabelece diretrizes para o desenvolvimento de ações em função do modelo de desenvolvimento adotado. Neste sentido, as diretrizes para a educação proposta pela Agenda 21 brasileira só podem ser analisadas à luz das diretrizes para o desenvolvimento que ela estabelece para o país.

O DESENVOLVIMENTO SUSTENTÁVEL NA A GENDA 21 BRASILEIRA: A INSERÇão do Brasil NA GLOBALIZAÇão

A proposta de desenvolvimento sustentável da Agenda 21 brasileira referencia-se na Agenda 21 global. Contudo, observa-se que a Agenda 21 brasileira propõe avanços em relação ao documento de referência, adaptando suas diretrizes não só às características do país como também ao desenvolvimento das discussões sobre a relação entre desenvolvimento e sustentabilidade, após a Cnumad de 1992. Dentre esses avanços, sugere a superação do absolutismo econômico presente nas diretrizes para o desenvolvimento sustentável. Para isto, a Agenda 21 brasileira considera que a dimensão econômica deve articular-se às demais dimensões do desenvolvimento sustentável: a ética (sobrevivência da espécie/gerações futuras), a temporal (que estabelece o princípio da precaução), a prática (mudança de hábitos e comportamentos, especialmente os relacionados ao consumo) e a dimensão social. Esta última estabelece a redução da desigualdade social e a inclusão social como fundamentos para a formação de uma sociedade solidária (MMA/PNUD/CPDS, 2000, 2002).

Além disso, a Agenda 21 brasileira enfatiza a noção de sustentabilidade ampliada e progressiva (MMA/PNUD/CPDS, 2002, p. 18-19). A sustentabilidade ampliada deve permear as dimensões econômica, social, territorial, científica e tecnológica, política e cultural. A sustentabilidade progressiva propõe a gestão dos conflitos no processo de desenvolvi- 
mento, pois considera que "não se deve aguçar os conflitos a ponto de torná-los inegociáveis, e, sim, fragmentá-los em fatias menos complexas, tornando-os administráveis no tempo e no espaço". Ainda no sentido de avançar em relação à Agenda 21 global, o documento brasileiro propõe um novo paradigma de desenvolvimento que se fundamenta em uma "globalização solidária" que incorpore os países em desenvolvimento e os países marginalizados (2002, p. 19).

Esses princípios regem o desenvolvimento sustentável no Brasil, que estabelece, como condição necessária, a melhoria das condições de inserção do país no capitalismo globalizado. O locus de inserção do país para a promoção de seu desenvolvimento já está, assim, definido. Restará à Agenda 21 brasileira a apresentação das diretrizes para essa inserção, mais precisamente, para a inserção na sociedade da informação, dos conhecimentos e dos serviços, considerada como um novo paradigma (2002, p. 19).

Ainda que a Agenda 21 brasileira considere os efeitos perversos da economia globalizada e, em contrapartida, afirme a necessidade de certa autonomia do país na adesão à globalização, esta não é problematizada. A crítica ao absolutismo econômico, do qual decorre a idéia de sustentabilidade ampliada, não esgota a discussão em torno das causas estruturais da insustentabilidade. Ainda, a idéia de uma sustentabilidade progressiva não pode velar a necessidade de analisar as causas estruturais dos conflitos em torno dos interesses sociais. Segundo Castells (2000, p. 166), administrar conflitos socioambientais não é só uma questão de torná-los menos complexos, mas é uma questão de entendê-los como se deve.

Pode-se considerar que o documento prévio à versão final da Agenda 21 brasileira apresentou certa preocupação com a inserção do país na globalização. A Agenda 21 brasileira - Bases para discussão (2000, p. vii), também afirma a necessidade de inserção do país no processo de globalização, mas com base nas seguintes ponderações:

processo que, sem dúvida envolve muitas conquistas, mas que também pode traduzir-se em ameaças para os países que não conseguirem inserirse vantajosamente na chamada "civilização do conhecimento". Qual será o melhor caminho a ser seguido por um país com as condições específicas para o Brasil? Que sistemas de educação, de ciência e tecnologia, por exemplo, serão capazes de assegurar-lhe o lugar adequado no mundo? 
Contudo, ao mesmo tempo em que propõe a inserção do Brasil na civilização do conhecimento, o mesmo documento, no tema "Construção da ciência e tecnologia para o desenvolvimento sustentável", reconhece que a racionalidade econômica que fundamenta a sociedade globalizada é causa da insustentabilidade:

A sustentabilidade emerge da crise de esgotamento das concepções de desenvolvimento enquadradas nas lógicas da racionalidade econômica. [...] A atividade econômica não se desenvolverá sustentavelmente se a natureza que lhe fornece os recursos materiais estiver gravemente comprometida. É uma questão de bom senso saber que os cuidados com o meio ambiente não podem emergir de um mercado agressivo com a biosfera [...] Os critérios de eficiência econômica de um sistema não podem mais repousar apenas nos critérios de ganhos de produtividade, e sim na capacidade de satisfazer as necessidades das pessoas ao menor custo ecológico e humano.

Mas como propor a inserção do Brasil no capitalismo globalizado, reconhecendo que é necessário transformar critérios que correspondem à sua natureza? Esta incompatibilidade se resolve na versão final da Agenda 21 brasileira, que se distancia das causas estruturais da insustentabilidade. A sociedade globalizada da informação, do conhecimento e dos serviços é vislumbrada como um horizonte a ser alcançado, pois não se reconhece a contradição entre o seu modelo de desenvolvimento e a sustentabilidade em todas as suas dimensões. Assim, o desenvolvimento sustentável proposto pela Agenda 21 brasileira mantém sua funcionalidade no sistema produtivo vigente. Torna-se um instrumento de adesão do Brasil a uma nova fase do desenvolvimento do capitalismo que se cristaliza no modelo da sociedade da informação e do conhecimento (MMA/PNUD/CPDS, 2002, p. 22).

Uma vez estabelecido o objetivo de inserção do Brasil no processo de globalização, qual o papel da educação para o desenvolvimento sustentável a partir dessa inserção? A Agenda 21 brasileira estabelece para a educação um papel importante no desenvolvimento das condições de inserção do país na globalização, ao propor a educação para a inclusão social. 
EdUCAÇÃo, INCLUSÃO SOCIAL E INSERÇ̃̃o DO BRASIL NA GLOBALIZAÇÃO

As diretrizes para a educação da Agenda 21 brasileira acompanharam a tendência de redução da análise crítica das causas da insustentabilidade existente na Agenda 21 brasileira-Bases para discussão. Neste documento, a educação foi considerada como uma variável fundamental para promover a redução das desigualdades sociais. $\mathrm{Na}$ Agenda 21 brasileira, a educação para redução da desigualdade social foi substituída pela educação para a inclusão social. Esta substituição atribui à educação a responsabilidade de atender a duas necessidades desta inclusão: a qualificação para o trabalho e a formação moral para a civilização planetária. Eis a sua contribuição para a promoção do desenvolvimento sustentável.

O item que trata majoritariamente da educação intitula-se "Objetivo 6: Educação permanente para o trabalho e a vida". Esse objetivo está ao lado da promoção da saúde, da distribuição de renda e do saneamento ambiental, fazendo parte do tema "Inclusão social para uma sociedade solidária" (2002, p. 42).

A educação se destaca ainda em dois outros objetivos da Agenda 21 brasileira: no "Objetivo 5: Informação e conhecimento para o desenvolvimento sustentável" e no "Objetivo 21: Pedagogia da sustentabilidade: ética e solidariedade".

O Objetivo 5 refere-se à educação para a ciência e tecnologia em todos os níveis de ensino, capacitando recursos humanos para que o Brasil possa inserir-se no topo da produção mundial da ciência e da tecnologia, criando condições de competição na globalização tecnológica. Através da educação científica e tecnológica, forma-se o cidadão em condições de desenvolvimento pessoal e inserção no mercado de trabalho, além de promover a geração e divulgação de conhecimento relacionado ao uso sustentável dos recursos naturais (2002, p. 40).

O Objetivo 21 encarrega-se da formação moral para a "boa governança". O referencial ético desta formação é a Carta da Terra, um conjunto de princípios e valores considerados necessários à promoção do desenvolvimento sustentável elaborado na Cnumad em 1992 e reconhecida pela ONU em 2000. Identificando uma crise moral na sociedade moderna, considera-se que a "civilização planetária" deve compartilhar os mesmos valores em torno de temas que afetam todos os seres 
humanos, particularmente o meio ambiente. A constatação de que há uma dependência entre natureza e sociedade justifica a necessidade de uma ética do cuidado e da compaixão (2002, p. 80). Segundo as ações recomendadas para se alcançar tal objetivo, caberia à educação divulgar esses princípios éticos nas escolas, nas universidades, nas empresas, no governo e na sociedade civil organizada.

Ressalte-se que o Objetivo 21 não se relaciona aos demais objetivos para a educação apresentados pela Agenda 21 brasileira, especialmente no que se refere à formação de recursos humanos para a sociedade do conhecimento e da informação. O objetivo de formação moral, isoladamente, nos remete à questão de Layrargues (2006, p. 97) sobre as possibilidades de uma educação que objetiva somente a mudança cultural. Ao analisar a educação ambiental hegemônica no Brasil, o autor questiona se somente a instauração de uma nova ética é suficiente para uma mudança ambiental. Mais especificamente: é possível uma mudança cultural sem uma mudança social? Para o autor, a resposta é negativa e, neste caso, a educação, na medida em que se exime de focar a mudança social, é um agente da reprodução social.

Ainda que a educação tenha sido referenciada em outros itens da Agenda 21 brasileira, a reflexão proposta neste artigo se concentrará no Objetivo 6, por ser este dedicado exclusivamente à educação e conter as principais diretrizes para o seu desenvolvimento.

O Objetivo 6 possui 4 subitens. Além do primeiro que o intitula - "Educação permanente para o trabalho e a vida", estão: "O analfabetismo funcional e o fortalecimento do ciclo básico", "A escola-cidadã contra a pedagogia da repetência" e "O saber prático e a educação profissional". Observa-se que está no título de dois subitens a relação entre educação e trabalho. Nos outros dois, embora esta relação não esteja nos títulos, está presente em seus textos.

No mesmo objetivo, destaca-se a relação entre a educação e as novas exigências do trabalho. A educação é mais um elemento que deve ser utilizado para que o Brasil possa se inserir na sociedade informacional ou do conhecimento. Na Agenda 21 brasileira-Bases para discussão, já se ressaltava a importância da educação para a formação voltada à sociedade do conhecimento "com a chamada Terceira Revolução Industrial e o conhecimento colocando-se no centro da dinâmica econômica como principal força produtiva - a educação ganha ainda maior importância" (MMA/PNUD/CPDS, 2000, p. 100). 
Para isso, a Agenda 21 brasileira considera que a educação deve ser permanente e continuada. Ela deve ser um processo contínuo de aprendizado que torna possível o pleno aproveitamento de potencialidades e o desenvolvimento moral, material e espiritual (MMA/PNUD/CPDS, 2002, p. 42). A continuidade da educação extrapola a formação escolar. Estende-se ao trabalho e às outras instâncias da vida social através de cursos de formação ou através da mídia. Assim, garante-se a atualização das informações, dos conhecimentos necessários à inclusão social (2002).

Desde o documento Agenda 21 brasileira-Bases para discussão observa-se que a educação é abordada, principalmente, sob a perspectiva da formação de recursos humanos. Ainda que considere o objetivo da educação mais amplo do que a simples formação para o trabalho, a educação deve responder às mudanças no mundo do trabalho, sobretudo a flexibilização do trabalho ou, segundo a Agenda 21 brasileira, ao trabalho que está em "permanente remodelagem" (2002). Como formar indivíduos adaptados à flexibilização? Através do desenvolvimento de "múltiplos dons e habilidades práticas que são a ferramenta necessária para atividades as mais diversas", ou seja, é necessário o "saber prático" (2002, p. 44).

É necessário ainda que haja educação de qualidade e melhoria da oferta de ensino. Isto requer a capacitação de professores, sob responsabilidade das universidades, e a participação dos pais no acompanhamento da aprendizagem de seus filhos e na administração escolar, inclusive na captação de recursos financeiros para a escola. A redução de custos financeiros deve ser realizada através do controle de desperdícios e da desburocratização da escola, com redução da excessiva especialização das ocupações docentes e técnicas (2002, p. 44-45).

Embora os objetivos específicos atribuídos à educação para o desenvolvimento sustentável possam ser analisados individualmente, uma reflexão sobre seu objetivo principal, ao qual os objetivos específicos estão subordinados, é a mais indicada. Nele estão os elementos para a compreensão da relação entre a educação proposta pela Agenda 21 brasileira e a inserção do Brasil na globalização, condição para o desenvolvimento sustentável proposto por este documento. Nele podemos identificar a funcionalidade da educação para o desenvolvimento sustentável.

A Agenda 21 brasileira trata a educação como fator de inclusão social na sociedade do conhecimento e da informação, visando à forma- 
ção de recursos humanos. Neste documento, o que se espera da educação segue as diretrizes da política educacional brasileira, na qual a educação é considerada como instrumento privilegiado para promover a inclusão social através do desenvolvimento de competências adequadas à sociedade contemporânea. A inclusão através do desenvolvimento de competências esgota, na educação, a discussão em torno da exclusão social.

Deve-se observar, no entanto, que a utilização da noção de exclusão social tem sido considerada uma noção geral que não considera as causas estruturais da desigualdade e da pobreza (FrÉTIGNÉ, 1999; WANDERLEY, 2001). Neste caso, a educação, como promotora da inclusão social, retira da discussão sobre o papel da educação na sociedade a sua responsabilidade no processo de reprodução das desigualdades sociais, prevalecendo a abordagem da educação para a integração social aos moldes da abordagem funcionalista da educação (TeIXEIRA, 2006).

Destacam-se aqui duas observações que colocam em questão o discurso no qual a educação é decisão acertada para a inclusão social. No caso da formação de recursos humanos, este discurso se sustenta, principalmente, na promessa da educação como garantia da inclusão no mercado de trabalho. Retomando o desenvolvimento sustentável, esta seria um fator de promoção da sustentabilidade social.

Primeiramente, na Agenda 21 brasileira, o tipo de conhecimento necessário para a inclusão social é o conhecimento que supervaloriza o saber prático sobre o conhecimento teórico ou sobre a formação humanista. Isto envolve o domínio da tecnologia informacional, considerado uma condição para a inclusão social. Contudo, deve-se observar que esta característica tem o sentido da instrumentalização, do saber fazer. Não é a produção do conhecimento sobre a realidade (social, do trabalho) que está sendo valorizado, mas a capacidade de assimilar o já produzido, tomado como indiscutível, e aplicá-lo em situações específicas. É uma competência orientada por parâmetros individuais e técnicos, guiada pelo determinismo tecnológico, que responde às exigências do mercado de trabalho, conforme já analisado por Ramos (2002).

Em segundo lugar, deve-se considerar que a capacitação obtida através da escolarização - e talvez possamos extrapolar para as outras possibilidades apresentadas pela Agenda 21 brasileira, como cursos e mídia - não garante emprego e remuneração para os sujeitos da inclusão social. A falta de identificação das causas estruturais da desigualdade social supervaloriza o papel da educação na resolução dos problemas 
sociais. Toma-se a parte pelo todo e desvia-se a discussão das causas estruturais da pobreza, alvo do desenvolvimento sustentável. Isto pode ser constatado em afirmações como:

a característica mais marcante da pobreza brasileira é o baixo nível educacional que faz com que o acesso dessas pessoas ao trabalho fique circunscrito aos postos não qualificados, de baixa produtividade e baixa remuneração. (MMA/PNUD/CPDS, 2000, p. 99).

Ou ainda, "a carência de educação é considerada a principal responsável por $40 \%$ da pobreza do país" (MMA/PNUD/CPDS, 2002a, p. 42).

Como demonstram alguns estudos sobre a expansão da educação brasileira nas duas últimas décadas (HASENBALG, 2003; Silva, 2003), a educação não fez tanto assim pela pobreza, desigualdade e exclusão social no país. Esses estudos confirmam a tendência de outros países, na qual a expansão do ensino não promoveu mobilidade social significativa e deslocou a exclusão para níveis superiores de formação no sistema de ensino. Dados obtidos por Dupas (1999) revelam que mesmo os escolarizados estão fadados a limitada oferta de emprego para os quais foram preparados.

A ideologia do sucesso através da educação voltada para a sociedade informacional e do conhecimento não encontra respaldo nos fatos. Ao se referir à escolarização, Pino (2003, p. 79) considera que, embora esta idéia seja compartilhada por trabalhadores e pela população em geral,

É ingênuo acreditar que é possível corrigir as distorções do mercado em função da qualificação dos trabalhadores e das trabalhadoras. Não é a escola que define o posto que o homem ou a mulher irá ocupar na produção. Ao contrário, muitas vezes o lugar que a família_do aluno ou da aluna ocupa na produção é que acaba levando o/a aluno/a para um determinado tipo de escola. Portanto, não é possível resolver a crise de emprego dentro da escola.

Mesmo os argumentos que afirmam que "sem ela seria pior" não podem velar o fato de que a inclusão obtida através da educação é a inclusão relativa. Ela inclui nas margens da sociedade, bem distante do seu centro. Segundo Bourdieu (1993, p. 11), os espaços sociais se multiplicam, possibilitando a inclusão, mas esta se caracteriza pelo desenvolvimento 
de "pequenas misérias". Reproduz-se assim a desigualdade social que, segundo a Agenda 21 - Bases para discussão, deve ser combatida para a promoção do desenvolvimento sustentável. Como foi visto anteriormente, esta perspectiva foi abandonada no documento seguinte.

As observações acima podem ser corroboradas com estudos que consideram as políticas e ações educacionais como respostas ao pensamento neoliberal e ao processo de reestruturação produtiva que caracterizam a economia globalizada, reafirmando a sua relação com a reprodução das desigualdades sociais (FrigotTo, 1998; GeNTILI, 1999).

A exclusão e a desigualdade têm causas estruturais que não podem ser superadas com a expansão de oportunidades de formação educacional, mesmo que fora do espaço escolar, mesmo que de qualidade, considerando a qualidade dentro dos referenciais da Agenda 21 brasileira. As causas estruturais são da natureza do sistema, não problematizado pela Agenda 21 brasileira, e no qual se deve inserir o país para a promoção do desenvolvimento sustentável. Uma vez acertada esta única via considerada para o desenvolvimento, formar-se-iam as condições para as sustentabilidades ambiental, ecológica, social, ética etc. Para a educação resta a função de atender às exigências colocadas pela via escolhida para o desenvolvimento sustentável do país.

\section{CONSIDERAÇÕES FINAIS}

A sustentabilidade social na Agenda 21 brasileira avançou em relação à noção de desenvolvimento sustentável da Agenda $21 \mathrm{global}$, abandonando a subjugação da sociedade à sustentabilidade ambiental. Porém, essa sustentabilidade social caiu em outra armadilha. Sua subjugação, agora, está voltada para o modelo de desenvolvimento econômico por ela adotado. As suas principais estratégias a ele se dirigem.

A Agenda 21 brasileira evidencia a tese da funcionalidade quando define que o caminho do desenvolvimento segue a inserção do país na sociedade globalizada. Nela, a educação é considerada como instrumento de promoção da inclusão social, mantendo assim a mesma lógica da integração à economia globalizada como condição para o desenvolvimento sustentável. A sua contribuição para a promoção da sustentabilidade social se realizará na formação para a inclusão no sistema responsável pela insustentabilidade. 
As diretrizes da Agenda 21 brasileira, inclusive aquelas relativas à educação, representam, em última instância, a conformidade com os efeitos perversos da globalização, uma vez que não foi construída na perspectiva da transformação, mas da adaptação. É a adaptação do crescimento econômico aos limites ambientais, é a adaptação dos problemas sociais à meta de inserção do país na economia globalizada. É a adaptação ao possível, na qual a educação contribui com a formação de recursos humanos para a sociedade da informação, do conhecimento etc.

Enfim, refletindo sobre a implantação da Agenda 21 brasileira, elevada à condição de Programa do Plano Plurianual do Governo (PPA 2004/2007), portanto, de política pública, deve-se conter as expectativas em relação às possibilidades de efetivas mudanças a partir do modelo de desenvolvimento sustentável adotado. Este modelo, uma vez efetivado, pode provocar avanços limitados como, por exemplo, o esforço de introduzir a dimensão ambiental na política de desenvolvimento do Estado. Mais precisamente, ainda que as causas estruturais da insustentabilidade permaneçam, os avanços podem ocorrer mesmo que, sob eles, se amontoem as conseqüências desta insustentabilidade, tais como a mudança climática, o esgotamento de recursos naturais, a desigualdade social, a pobreza etc. Analogamente, Walter Benjamin já teria revelado o mesmo processo ao descrever o sentido da história:

Há um quadro de Klee que se chama Angelus Novus. Representa um anjo que parece querer afastar-se de algo que ele encara fixamente. Seus olhos estão escancarados, sua boca dilatada, suas asas abertas. O anjo da história deve ter esse aspecto. Seu rosto está dirigido para o passado. Onde nós vemos uma cadeia, ele vê uma catástrofe única, que acumula incansavelmente ruína sobre ruína e as desprezam os nossos pés. Ele gostaria de deter-se para acordar os mortos e juntar os fragmentos. Mas uma tempestade sopra do paraíso e prende-se em suas asas com tanta força que ele não pode mais fechá-las. Essa tempestade o impele irresistivelmente para o futuro, ao qual ele vira as costas, enquanto o amontoado de ruínas cresce até o céu. Essa tempestade é o que chamamos progresso. (BENJAMIN, 1986, p. 226)

O desenvolvimento sustentável que, segundo Becker (1999), reencanta o progresso, empurra a história sobre os escombros. A educação para o desenvolvimento sustentável proposta pela Agenda 21 brasileira, abandonando a utopia da transformação social, parece acompanhar a nova tempestade. 


\begin{abstract}
This paper analyzes the educational guidelines of the Brazilian Agenda 21, presented as a tool for planning sustainable development, whose aim is to establish compatibility between environmental conservation, social justice and economic growth. According to the Brazilian Agenda 21, education should promote social inclusion and thereby, contribute towards placing Brazil in the global market. The presence of Brazil in the global market is considered a condition for sustainable development. However, it can be seen that the proposals for education are, in the final analysis, a means of inserting Brazil into the very economic model which is at the root of unsustainable development.
\end{abstract}

Keywords: Education and sustainable development. Brazilian Agenda 21.

\title{
REFERÊNCIAS
}

BECKER, D. F. Sustentabilidade: um novo (velho) paradigma de desenvolvimento regional. In: BECKER, D. F. (Org.). Desenvolvimento sustentável. Necessidade ou possibilidade. 2. ed. Santa Cruz do Sul, SC: EDUNISC, 1999. p. 27-94.

BENJAMIN, W. Magia e técnica, arte e história. 2. ed. São Paulo: Brasiliense, 1986.

BOURDIEU, P. L'espace des points de vue. In: BOURDIEU, P. (Org.) La misère du monde. Paris: Seuil, 1993. p. 9-11.

BRASIL. MINISTÉRIO DO MEIO AMBIENTE. Agenda 21 brasileira. Apresentação. Disponível em: <http://www.mma.gov.br/index.php?ido=conteudo. monta\&idEstrutura=18\&idConteudo=908>. Acesso em: 12 fev. 2007.

Agenda 21 brasileira. Disponível em: $<\mathrm{http}: / / \mathrm{www} . \mathrm{mma}$.gov.br/?id_ estrutura $=18$ \&id_conteudo $=908>$. Acesso em: 8 mai. 2005a

Programa Agenda 21 - PPA. Disponível em: <http://www.mma.gov.

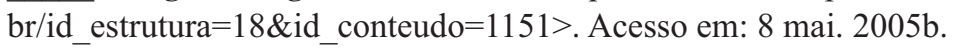

BRASIL. MINISTÉRIO DO MEIO AMBIENTE. PROGRAMA DAS NAÇÕES UNIDAS PARA O DESENVOLVIMENTO. COMISSÃO DE POLÍTICAS DE DESENVOLVIMENTO SUSTENTÁVEL DA AGENDA 21 NACIONAL. Agenda 21 Brasileira. Ações prioritárias. Brasília, 2002. Disponível em: $<$ http://www.mma.gov.br/port/se/agen21/doc/acoesprio.pdf $>$. Acesso em: 24 abr. 2004. 2000.

.Agenda 21 brasileira. Bases para discussão. Brasília: MMA/PNUD, 
CASTELlS, M. O poder da identidade. São Paulo: Paz e Terra, 1999. (A era da informação: economia, sociedade e cultura; v. 2).

DALE, R. Globalização e educação: demonstrando a existência de uma "Cultura educacional mundial" ou localizando uma "agenda global estruturada para a educação"? Educação e sociedade. Campinas, SP: v. 25, n. 87, maio/ago., 2004. p. 423-460.

DUPAS, G. Economia global e exclusão social. Pobreza, emprego, Estado e o futuro do capitalismo. São Paulo: Paz e Terra, 1999.

FOLLADORI, G. Los límites del desarrollo sustentable. Revista Trabajo e Capital. Montevideo: Ediciones de la Banda Oriental, 1999.

FRÉTIGNÉ, C. Sociologia de l'exclusion. Paris: L'Harmattan, 1999.

FRIGOTTO, G. (Org.). Educação e crise do trabalho: perspectivas de final de século. Petrópolis, RJ: Vozes, 1998.

GENTILI, P. (Org.) Globalização excludente: desigualdade, exclusão e democracia na nova ordem mundial. Petrópolis, RJ: Vozes, 1999.

HABERMAS, J. A crise de legitimação no capitalismo tardio. Rio de Janeiro: Tempo Brasileiro, 1980.

HASENBALG, C. A transição escolar para o mercado de trabalho. In: HASENBALG, C.; SILVA, N. de V. (Org.). Origens e destinos: desigualdades sociais ao longo da vida. Rio de Janeiro: IUPERJ/UCAM/Topbooks/FAPERJ, 2003. p. 147-162.

LAYRAYGUES, P. P. Muito além da natureza: educação ambiental e reprodução social. In: LOUREIRO, C.B.; LAYRARGUES, P.P.; CASTRO, R.S. (Org.). Pensamento complexo, dialética e educação ambiental. São Paulo: Cortez, 2006, p. 72-103.

LEFF, E. Ecologia, capital e cultura. Racionalidade ambiental, democracia participativa e desenvolvimento sustentável. Blumenau, SC: EDIFURB, 2000.

LEIS, H. R. A modernidade insustentável. As críticas do ambientalismo à sociedade contemporânea. Petrópolis, RJ: Vozes; Florianópolis, SC: Editora da UFSC, 1999.

. Globalização e democracia após a Rio-92: a necessidade e oportunidade de um espaço público transnacional. In: FERREIRA, L. C; VIOLA, E. (Org.). Incertezas da sustentabilidade na globalização. Campinas, SP: Editora da Unicamp, 1996. p. 67-91.

LÉLÉ, S. M. Sustainable development: A critical review. World Development. Great Britain, Pergamon Press, 19(6), p. 607-21, 1991. 
PINO, M. Política educacional, emprego e exclusão social. In: GENTILI, P.; FRIGOTTO, G. (Org.). A cidadania negada: políticas de exclusão social na educação e no trabalho. 3. ed. São Paulo: Cortez; Buenos Aires: CLACSO, 2002. p. 65-88.

RAMOS, M. N. A educação profissional pela pedagogia das competências: para além da superfície dos documentos oficiais. Educação e sociedade. Campinas, SP: v. 23, n. 80, 2002.

SILVA, N. do V. Expansão escolar e estratificação educacional no Brasil. In: HASENBLG, C.; SILVA, N. de M. (Org.). Origens e destinos: desigualdades sociais ao largo da vida. p. 105-146.

TEIXEIRA, C. Exclusão social e educação: questões para pensar a inclusão social. In: SCHMIDT, M. A.; STOLTZ, T. (Org.). Educação, cidadania e inclusão social. Curitiba: Aos quatro Ventos, 2006. p. 73-81.

VARGAS, P. R. O insustentável discurso da sustentabilidade. In: BECKER, D. F. (Org.). Desenvolvimento sustentável. Necessidade ou possibilidade. 2. ed. Santa Cruz do Sul, RS: EDUNISC, 1999. p. 207-236.

WANDERLEY, M. B. Refletindo sobre a noção de exclusão. In: SAWAIA, B. (Org). As artimanhas da exclusão social. Petrópolis, RJ: Vozes, 2001. p. 16-26. 